\title{
Collusion-Proof Mechanism in Compensation for Failed Generic Technological Innovation Projects: Based on Information Topology
}

\author{
Fan ZHANG, Jianmu YE, Congzhen XIE
}

\begin{abstract}
Against the backdrop of innovation fault-tolerance, government compensation for failed generic technological innovation projects is beneficial to stimulate reinnovation behaviour. However, considering the information asymmetry, a collusion tendency exists between the compensated party and the evaluator during the process of compensation. To prompt the government to build collusion-proof mechanisms to reduce collusion loss, the evolutionary game method was used to build replicated dynamic equations and a Jacobian matrix of both sides based on the information topology between the conspirators and regulator. Through the evolutionary equilibrium analysis and numerical simulation, evolutionary stability strategies (ESS) under different topological relationship information (non-intersect, partial intersect, and inclusive type) were found. Results show that the collusion behaviour can be effectively restrained when the government is unaware of collusion information, the net defense income is positive, and the penalty threshold is the product of the net collusive income and the ratio of the collusive and regulatory information. With the increasing amount of collusive information available to the government, the conspirators tend to adhere to moral principles subject to strict regulation. In addition, the moderating effect of penalty factor is positively correlated with the private information possessed by both sides. The conclusion is beneficial to provide theoretical support for optimizing the governmentled compensation mechanism for failed generic technological innovation projects.
\end{abstract}

Keywords: collusion-proof mechanism; compensation for failure; evolutionary game; failed generic technological innovation projects; information topology

\section{INTRODUCTION}

The theory of endogenous growth shows that technological progress is the decisive factor in economic growth. Particularly, as a typical quasi-public good, the outcome of generic technological innovations can be shared by the entire industry, which will have a profound impact on the target technical area and related enterprises. However, the positive externality of technological innovations will inevitably lead to problems, such as market failure and insufficient investment in innovation actions. Apart from the market force, these actions facilitate the promotion of policy tools as an effective means to compensate for the externality of generic technological innovations [1]. Moreover, the problem of innovation incentive efficiency loss has attracted increasing attention in theoretical and business circles. Although relevant scholars believe that the government innovation subsidy is an important reference factor for innovation investment of enterprises, the difference of mode and intensity of subsidy has a crowding-out effect on the investment and efficiency of enterprise innovation. The crowding-out effect leads to the regular occurrence of rent seeking due to information asymmetry between the government and enterprise [2, 3]. Therefore, the investment level of generic technological innovation has been restrained by the crowding-out effect of governmental innovation incentive policy to a certain extent, thus evidently reflecting the efficiency loss of incentive policy $[4,5]$. In this case, improvement of the effectiveness of innovation incentive has become an issue of intensive debate in society $[6,7]$.

Existing innovation incentive policies that support technological innovation mainly include policies on fiscal and taxation, special funds, procurement, and finance. These policies mostly focus on successful innovation or the front end of the technological innovation process. Attention on incentives for innovation failure is insufficient due to the existence of anti-failure bias [8, 9]. Furthermore, experimental principles of technological innovation contributed to the considerable uncertainty of technological innovation projects. The increasing intensity of market competition and innovation difficulties have also aggravated the high risk of technological innovation projects, thus leading to their failure. The commercial success rate of technological innovation projects is only $30 \%$ for AMD Inc. in the USA and other firms [10]. Meanwhile, according to the survey of technical innovation projects, 1884 of 2130 firms in the six major industries of China had existing technological innovation activities that were either suspended or failed, accounting for $88.45 \%$ of projects. Thus, the failure of technological innovation projects is objective. The high uncertainty of generic technological innovation projects has been determined by the experimental nature of generic technological innovations, while the high risk will be further aggravated by the intensity of market competition and the complexity of innovation dimension. Therefore, technically and systematically speaking, generic technological innovation projects often face higher risks of failure than general technological innovation projects. Meanwhile, if further exploiting, then many failed generic technological innovation projects may still have the opportunity and potential for success. Occasionally, this potential may even be better than the original research design. Against the backdrop of innovation fault tolerance, the effective compensation of the government for failed generic technological innovation projects will stimulate the re-innovation behaviour and improve the re-innovation performance of failed projects. At present, some projects that failed in generic technological innovation, such as qualified enterprises or projects devoted to biopharmaceutical research \& development, have been compensated by local governments and will be given a certain compensation for risk-taking. Within the industryoriented framework formulated by the government, the priority on project audit and support for tax reduction in terms of application, funding, and acceptance of generic technological innovation projects could be strengthened. The identification and evaluation of innovation failure are generally in the form of third-party delegations. However, 
no specific prevention mechanism for potential collusion between the compensated party and the evaluator is available.

In the compensation process for generic technological innovation failures, each participant considers how to make full use of the existing resources to maximize its own benefits. Due to the differences in objectives, it is very difficult to achieve unity among the supplier, the demander and the evaluator in prevention mechanism in current research. This paper proposes an internal mechanism consisting of the government, failed generic technological innovation projects and the third-party evaluator to analyse the relationships between the compensation players so as to explore the collusion-proof mechanism for compensation activities.

\section{LITERATURE REVIEW}

Arrow introduced technological progress into the economic growth model to reveal the important role of technological innovation in economic growth [11]. However, in the process of technological innovation development, generic technological innovation has spillover effect characteristics of the typical public products. This condition makes it difficult for the enterprise to obtain all surplus profits from generic technological innovations and, reduce the return from firm private investment, and restrict the motive force of generic technological innovation. Solving the problem of insufficient investment in generic technological innovations by solely relying on the allocation and adjustment of resources in the market is difficult. Most scholars believe that the use of policy tools is an effective means to compensate for the externality of generic technological innovation. Using R\&D subsidies, tax incentives, and government procurement to support and compensate for generic technological innovations can reduce the investment pressure and the risk perception of generic technological innovations to a certain extent and improve the expected income of generic technological innovations and the enthusiasm of R\&D investment [1214]. With regard to the relationship between government subsidy and generic technological innovation, some scholars believe that government subsidy also has a "crowding-out effect" or "substitution effect" on generic technological innovations [15]. Government subsidy will have an incentive effect on investments of generic technological innovation within a moderate range. However, an excessively large subsidy will produce a "crowding-out effect" on private innovation input $[16,17]$. The compensation game relationship between the government and the enterprise has always been the focus of the debate in the field of innovation incentive.

Owing to the uncertainty and high risk of generic technological innovation, the failure of generic technological innovation objectively exists [18]. In theory and in practice, the failure of generic technological innovation and the innovation incentive policy has gained increasing attention. Mining the internal value of the failed generic technological innovation is believed to have an important influence on improving the ability of independent innovation and intensifying the existing innovative resources. The failure problems originate from failure theory and gradually extend to the failure project research $[19,20]$. With regard to the definition of the concept of innovation, Schumpeter clearly indicated that the achievement of expected earnings was the main symbol to determine the success of innovation. With the in-depth understanding of generic technological innovation, the examination on achieving innovation goals (the standard of innovation failure) has also become diverse. For example, establishing an effective market through generic technological innovation and considering numerous factors, such as socials, economic, and ecological benefits, possibly leads to the lack of a unified and clear consensus for the criteria on innovation failure in extant literature [21].

Considering the government's lack of professionalism in the evaluation process of compensation targets, obstructions in accessing information regarding innovation failure and the possibility of rent seeking occurred in the government. According to the principle of information efficiency, the independent third-party agency with scale effect will be introduced for acquisition and evaluation of information. For failed projects, obtaining third-party verification may involve collusion with the third party to seek rent by disclosing false information. In the absence of collusion-proof mechanism, the third party may cater to the firm to defraud compensation products provided by the government. This condition will drive out "good money" in the potential compensation object and damage the entire social innovative efficiency and effectiveness.

As previously mentioned, the government innovation subsidy has solved the market failure problem due to positive externalities of generic technological innovation and insufficient investment from the enterprise to a certain extent. However, the rent-seeking potential in the process of innovation incentives raises the problem of incentive efficiency [22]. The introduction of the third party aims to select and evaluate compensation objects of generic technological innovation failures. In this case, the enterprise tends to collude with the third party to defraud the government subsidy, which will damage the entire interest of the society [23]. Therefore, existing research has difficulty forming relatively clear conclusions on the following questions: how can one build the corresponding collusion-proof mechanism to solve the problem of adverse selection, information acquisition, and collusion occurrence? How can a third party be given full play in the process of compensation to form a complementary relationship with the government? How can the shortage of government with inefficient supervision be covered and the effectiveness and precision of innovation incentives be improved?

\section{METHODLOGY}

In summary, the failed projects, as the compensation objects, have superiority in information with regard to the process of compensation for generic technological innovation failure. Therefore, the government must introduce professional third-party evaluators to identify potential false information. Considering that each participant tends to maximize their own benefits, achieving incentive compatibility among suppliers, demanders, and evaluators in the compensation process is difficult. A 
collusion tendency possibly exists between the demander and the evaluator while the supplier has to prevent potential collusive risks. As a result, the information topology between the conspirators ( $P E$ for short) and the government ( $G$ for short) will be established in this study based on information asymmetry, and then collusion-proof mechanism led by government can be designed. Through dynamic game under the asymmetric information, collusive risks and corresponding countermeasures can be revealed to deal with the problem of adverse selection and collusion after the introduction of the third party in the process of compensation.

\subsection{Four Types of Information Topology}

Information topological characteristics: In the construction process of the compensation selection model under information asymmetry, the failure information of generic technological innovation projects and the selection information of the third party are mostly private information, while the recognition and acquisition capacity of government are limited. Meanwhile, the compensation range and intensity, supervision willingness, and overall capacity of the government are mostly private information, while the acquisition capacity of the failed projects and the third party is limited. Therefore, the introduction of information topology between the fraud and defender to describe the asymmetric degree of information involves setting $I_{G}$ as information of the government $\left(I_{G} \in(0,1]\right), I_{P E}$ as information of the failed projects and the third party $\left(I_{P E} \in(0,1]\right)$, and $I_{G \cap P E}$ as shared information.

Owing to the privacy of collusive behaviour and the confidentiality of the government's supervision will, mode, and capacity, the information of conspirators is inconsistent with that of the defender. With regard to the information held by both parties as a set with boundaries, the inclusion relation of two types of information may be as follows:

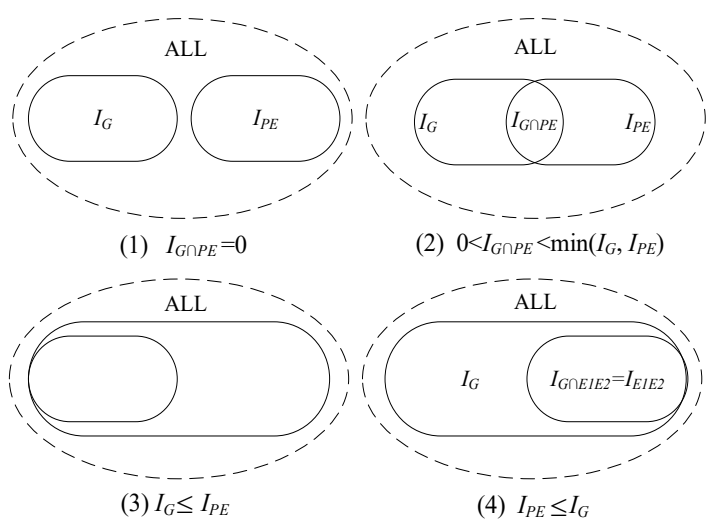

Figure 1 Four types of information topology

(1) The two types of information have no interference $\left(I_{G \cap P E}=0\right)$. (2) The two types of information are partly intersected $\left(0<I_{G \cap P E}<\min \left(I_{G}, I_{P E}\right)\right)$. (3) $I_{G}$ is contained in $I_{P E}$ (i.e., $I_{G \cap P E}=I_{G}$ ). (4) $I_{P E}$ is contained in $I_{G}$ (i.e., $I_{G \cap P E}=$ $\left.I_{P E}\right)$. The diagram of the information topology of compensation for failed generic technological innovation projects can be constructed based on the aforementioned classification (Fig. 1).

\subsection{The General Setting}

Behavioral agents in collusion-proof mechanism and their strategies: as the compensated party, the failed generic technological innovation project must disclose relevant information regarding its failure to obtain compensation from the government. The third-party agency is commissioned by the government as a selector of compensation object and an evaluator of compensation effect. From the perspective of determining the collusion of the failed project with the third party, the behavioral strategies of (collusion, non-collusion) are respectively recorded as $S_{P E}=\left(\alpha_{1}, \alpha_{2}\right)$. The government, which is the supervisor and defender in the selection and evaluation of compensation object, has behavioral strategies (regulation, non-regulation) respectively recorded as $S_{G}=\left(\beta_{1}, \beta_{2}\right)$.

Characteristics of bounded rationality: In reality, comparing the players cannot be perfectly rational but often rational on a limited basis [24, 25]. Bounded rationalities of the defender are mainly expressed as supervision will, which is determined through the strategy selection of the government with setting $\rho$ as selection probability of $\beta_{1}$ and $1-\rho$ as selection probability of $\beta_{2}$. Bounded rationalities of the collusive parties are also mainly expressed as their own moral constraints and interpretation of the supervision [26]. For the collusive parties, apart from economic interests of rent seeking, their moral constraint and interpretation of the supervision will also influence collusive behavior. Collusion behaviors would occur only when the collusive parties tend to break their own moral bottom line and show fear of supervision deterrence. Suppose that the probability of morality undone is $\lambda$, and the probability of ignorance of the supervision deterrent is $\omega$; then, $\alpha_{1}=\lambda \omega$ and $\alpha_{2}=1-\lambda \omega$.

Costs and benefits of game model: Set $V_{G}$ as the benefit of strict supervision, $C_{G}$ as the cost of strict supervision, $L_{G}$ as the loss of government, $V_{P E}$ as the benefit of collusion, $C_{P E}$ as the cost of collusion, and $F_{P E}$ as the punish factor for collusion (Tab. 1).

T| Table 1 Definition of Main Variables
\begin{tabular}{|c|c|l|}
\hline Num & Variable & \multicolumn{1}{c|}{ Definition } \\
\hline$(1)$ & $I_{G}$ & information of the government \\
\hline$(2)$ & $I_{P E}$ & $\begin{array}{l}\text { information of the failed projects and the third } \\
\text { party }\end{array}$ \\
\hline$(3)$ & $I_{G \cap P E}$ & shared information \\
\hline$(4)$ & $\rho$ & selection probability of regulation \\
\hline$(5)$ & $\lambda$ & the probability of morality undone \\
\hline$(6)$ & $\omega$ & $\begin{array}{l}\text { the probability of ignorance of the supervision } \\
\text { deterrent }\end{array}$ \\
\hline$(7)$ & $V_{G}$ & the benefit of strict supervision \\
\hline$(8)$ & $C_{G}$ & the cost of strict supervision \\
\hline$(9)$ & $L_{G}$ & the loss of government \\
\hline$(10)$ & $V_{P E}$ & the benefit of collusion \\
\hline$(11)$ & $C_{P E}$ & the cost of collusion \\
\hline$(12)$ & $F_{P E}$ & the punish factor for collusion \\
\hline
\end{tabular}

\subsection{Evolutionary Game Model}

In this study, the collusion-proof game model has been constructed in accordance with behavior relationships between the collaborator and the defender to explore collusive risk and collusion-proof mechanism under information asymmetry (Fig 2) [27]. Based on collusionproof payoff matrix in Fig. 2, replicator dynamics equation 
is built as follows:

$\frac{\mathrm{d} \theta(t)}{\mathrm{d} t}=\theta(t) \times\left[\mu_{t}(s)-\bar{\mu}_{t}\right]$

where $S$ is the collusive strategy set, $S_{G}=\left(\alpha_{1}, \alpha_{2}\right), S_{P E}=\left(\beta_{1}\right.$, $\left.\beta_{2}\right) ; \mathrm{d} \theta(t) / \mathrm{d} t$ is the growth rate of population ratio when the players choose some kind of strategy $S$ at time $t ; \theta(t)$ is the population ratio when the player selects the strategy $\mathrm{S} ; u t(s)$ is the benefit of the player from this strategy; and $\bar{\mu}_{t}$ is the average revenue.

According to the collusion-proof game tree, the absolute return and average earnings of conspirators with different collusion strategies are expressed as follows:

$$
\begin{aligned}
E \mu_{P E}^{\alpha_{1}} & =I_{P E}\left(V_{P E}-C_{P E}\right)-\rho I_{G \cap P E} V_{P E}-, \\
& -\rho\left(I_{G}-I_{G \cap P E}\right) F_{P E} \\
E \mu_{P E}^{\alpha_{2}}= & 0, \\
\bar{\mu}_{P E}= & \lambda \omega\left[I_{P E}\left(V_{P E}-C_{P E}\right)-\rho I_{G \cap P E} V_{P E}-\right. \\
& \left.-\rho\left(I_{G}-I_{G \cap P E}\right) F_{P E}\right]
\end{aligned}
$$

The absolute return and average earning of the government with different collusion strategies are expressed as follows:

$$
\begin{gathered}
E \mu_{G}^{\beta_{1}}=I_{G}\left(V_{G}-C_{G}\right)+\lambda \omega I_{G \cap P E} L_{G}-\lambda \omega I_{P E} L_{G}, \\
E \mu_{G}^{\beta_{2}}=-\lambda \omega I_{P E} L_{G}, \\
\bar{\mu}_{G}=\rho\left[I_{G}\left(V_{G}-C_{G}\right)+\lambda \omega I_{G \cap P E} L_{G}-\lambda \omega I_{P E} L_{G}\right] \\
-\lambda \omega(1-\rho) I_{P E} L_{G} \\
F(\lambda \omega)=\frac{\mathrm{d} \lambda \omega}{\mathrm{d} t}=\lambda \omega(1-\lambda \omega)\left[I_{P E}\left(V_{P E}-C_{P E}\right)\right. \\
\left.\quad-\rho I_{G \cap P E} V_{P E}-\rho\left(I_{G}-I_{G \cap P E}\right) F_{P E}\right] \\
F(\rho)=\frac{d \rho}{d t}=\rho(1-\rho)\left[I_{G}\left(V_{G}-C_{G}\right)+\lambda \omega I_{G \cap P E} L_{G}\right]
\end{gathered}
$$

From Eqs. (8)-(9), the Jacobian matrix can be computed as follows:

$\boldsymbol{J}(\lambda \omega, \rho)=\left(\begin{array}{ll}\frac{\partial F(\lambda \omega)}{\partial \lambda \omega} & \frac{\partial F(\lambda \omega)}{\partial \rho} \\ \frac{\partial F(\rho)}{\partial \lambda \omega} & \frac{\partial F(\rho)}{\partial \rho}\end{array}\right)$

\begin{tabular}{|c|c|c|c|c|}
\hline Variable Value & Equilibrium Point & $\operatorname{DetJ}(\lambda \omega, \rho)$ & $\operatorname{TrJ}(\lambda \omega, \rho)$ & Stability \\
\hline \multirow{4}{*}{ 1(a) $V_{G}>C_{G}$ and $F_{P E}<\frac{I_{P E}\left(V_{P E}-C_{P E}\right)}{I_{G}}$} & $\mathrm{E}(0,0)$ & + & + & instability \\
\hline & $\mathrm{E}(0,1)$ & - & uncertainty & saddle point \\
\hline & $\mathrm{E}(1,0)$ & - & uncertainty & saddle point \\
\hline & $\mathrm{E}(1,1)$ & + & - & ESS \\
\hline \multirow{4}{*}{ 1(b) $V_{G}>C_{G}$ and $F_{P E}>\frac{I_{P E}\left(V_{P E}-C_{P E}\right)}{I_{G}}$} & $\mathrm{E}(0,0)$ & + & + & instability \\
\hline & $\mathrm{E}(0,1)$ & + & - & ESS \\
\hline & $\mathrm{E}(1,0)$ & - & uncertainty & saddle point \\
\hline & $\mathrm{E}(1,1)$ & - & uncertainty & saddle point \\
\hline \multirow{4}{*}{ 1(c) $V_{G}<C_{G}$ and $F_{P E}<\frac{I_{P E}\left(V_{P E}-C_{P E}\right)}{I_{G}}$} & $\mathrm{E}(0,0)$ & - & uncertainty & saddle point \\
\hline & $\mathrm{E}(0,1)$ & + & + & instability \\
\hline & $\mathrm{E}(1,0)$ & + & - & ESS \\
\hline & $\mathrm{E}(1,1)$ & - & uncertainty & saddle point \\
\hline \multirow{4}{*}{ 1(d) $V_{G}<C_{G}$ and $F_{P E}>\frac{I_{P E}\left(V_{P E}-C_{P E}\right)}{I_{G}}$} & $\mathrm{E}(0,0)$ & - & uncertainty & saddle point \\
\hline & $\mathrm{E}(0,1)$ & - & uncertainty & saddle point \\
\hline & $\mathrm{E}(1,0)$ & + & - & ESS \\
\hline & $\mathrm{E}(1,1)$ & + & + & instability \\
\hline
\end{tabular}



Figure $2 \mathrm{Game}$ tree of collusion-proof mechanism

\section{RESULT AND ANALYSIS}

\subsection{Information Topology with Non-Intersect Type}

When information of the conspirators is inconsistent with that of the defender (i.e., $I_{G \cap P E}=0$ ), the sign symbol of $\operatorname{DetJ}(\lambda \omega, \rho)$ and $\operatorname{TrJ}(\lambda \omega, \rho)$ can be determined by Eq. (10), which will obtain the evolutionary stable strategy (ESS) and replicated dynamic equation (Tab. 2).

Table 2 Equilibrium Point and Stability Analysis in Case $I_{G \cap P E}=0$

As shown in Tab. 2, when the information of the collaborator is inconsistent with that of the defender, the following results can be concluded. (1) If the net earning of government from collusion-proof behavior is positive 
and the penalty factors $F_{P E}$ are larger than threshold $I_{P E}$ $\left(V_{P E}-C_{P E}\right) / I_{G}$, then the equilibrium strategy of the conspirators is non-collusion $\left(\alpha_{2}\right)$; otherwise, collusion $\left(\alpha_{1}\right)$ (2) If the net earnings of government from collusion-proof behavior is positive, then the equilibrium strategy of the government is regulation $\left(\beta_{1}\right)$; otherwise, non-regulation $\left(\beta_{2}\right)$. Therefore, assuming any player cannot obtain information from each other, if the net earning of the government is positive and the penalty factors are larger than the threshold, then the ESS is $\left(\alpha_{2}, \beta_{1}\right)$. This finding means that the failed generic technological innovation projects and the third party do not demonstrate a collusion tendency (i.e., $\lambda=0$ or $\omega=0$ ), while the government tends to keep these projects under strict supervision.

Based on parameter assignment, a sample phase portrait for $P E$ and $G$ under the replicator dynamics in Case 1(a) is given in Figure 3(1). Of the four stationary points of this phase portrait, only $(\lambda \omega=1, \rho=1)$ is asymptotically stable. The three other stationary points are unstable. A similar portrait exists in Cases 1(b), 1(c), and 1(d), and the behavior in each of these cases is analogous (Fig. 3(1)3(4)).
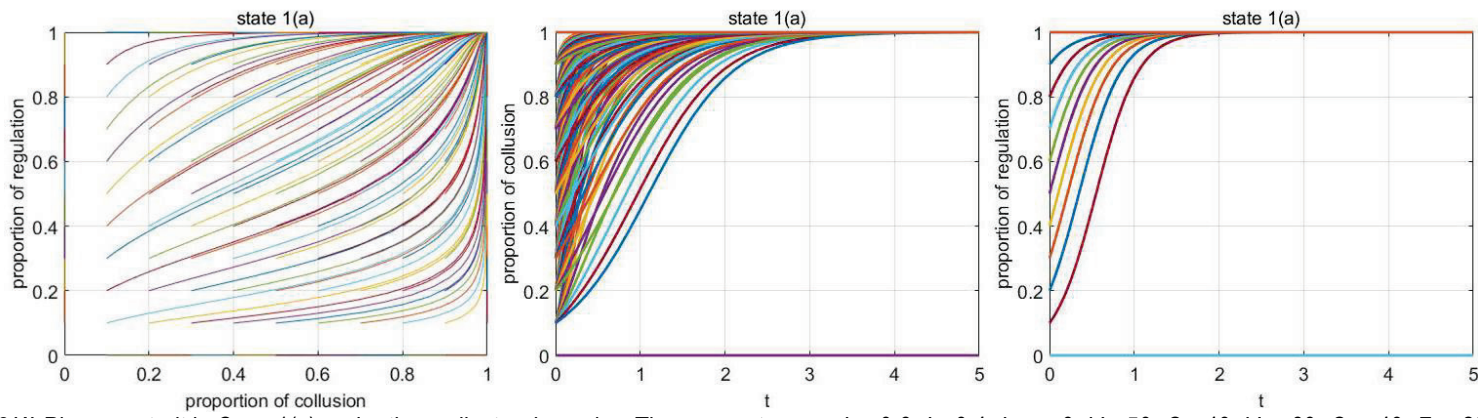

Figure 3(1) Phase portrait in Case 1 (a) under the replicator dynamics. The parameters are $I_{P E}=0.6, I_{G}=0.4, I_{G \cap P E}=0, V_{G}=50, C_{G}=40, V_{P E}=60, C_{P E}=40, F_{P E}=25, L_{G}=20$
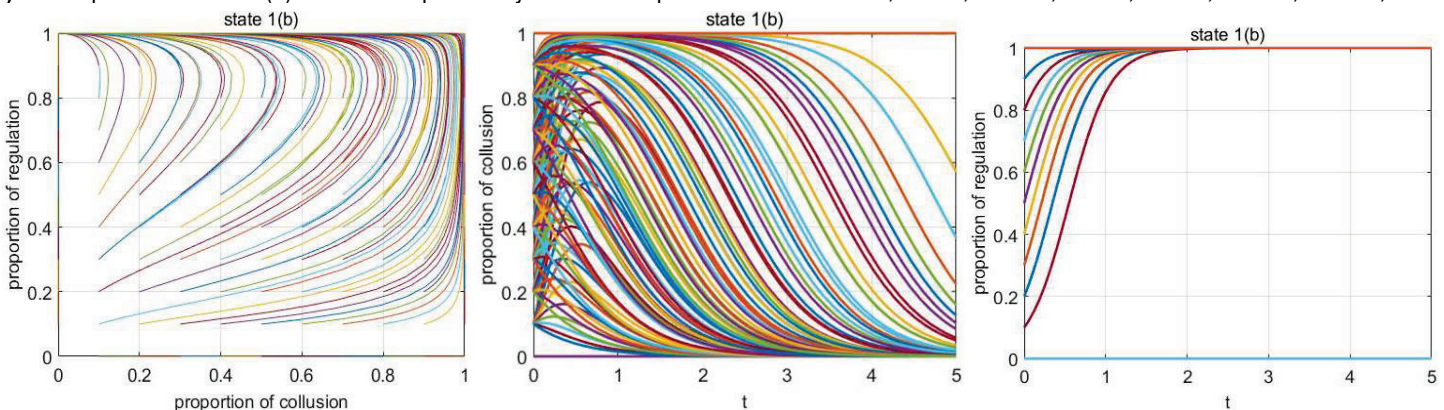

Figure 3(2) Phase portrait in Case $1(\mathrm{~b})$ under the replicator dynamics. The parameters are $I_{P E}=0.6, I_{G}=0.4, I_{G \cap P E}=0, V_{G}=50, C_{G}=40, V_{P E}=60, C_{P E}=40, F_{P E}=35, L_{G}=20$
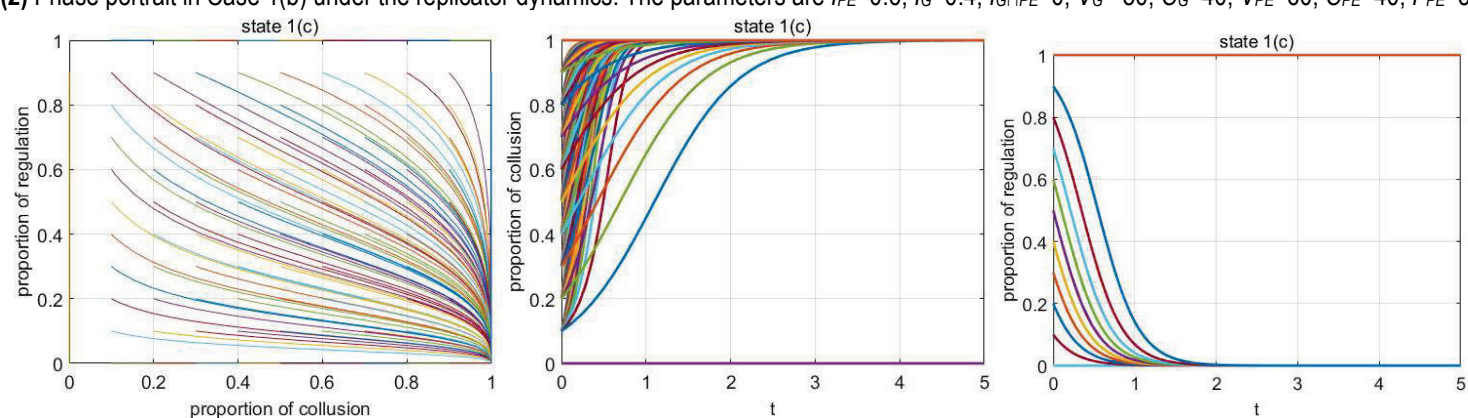

Figure 3(3) Phase portrait in Case 1 (c) under the replicator dynamics. The parameters are $I_{P E}=0.6, I_{G}=0.4, I_{G \cap P E}=0, V_{G}=20, C_{G}=30, V_{P E}=60, C_{P E}=40, F_{P E}=25, L_{G}=20$
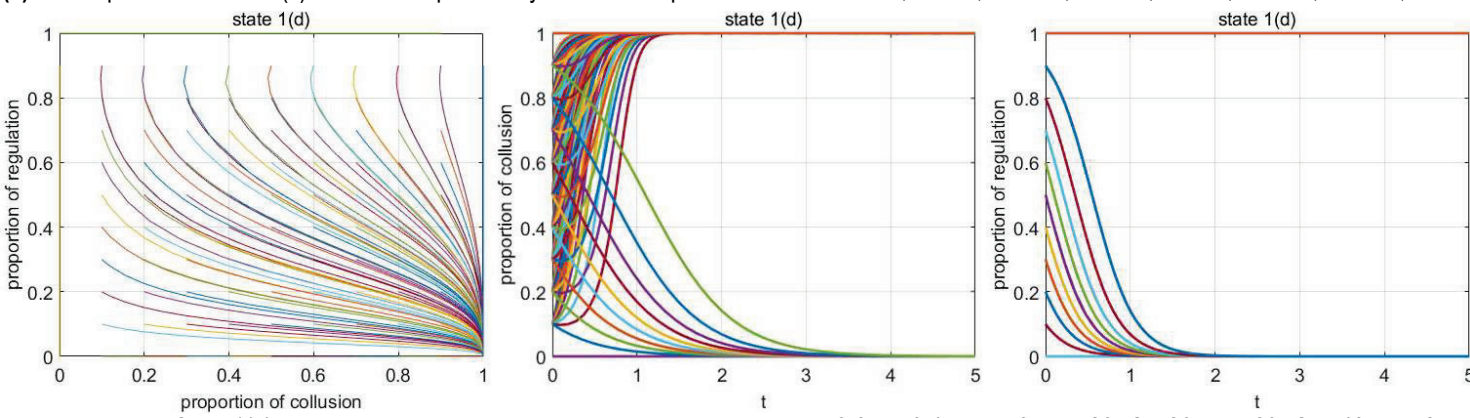

Figure 3(4) Phase portrait in Case $1(\mathrm{~d})$ under the replicator dynamics. The parameters are $I_{P E}=0.6, I_{G}=0.4, I_{G \cap P E}=0, V_{G}=20, C_{G}=30, V_{P E}=60, C_{P E}=40, F_{P E}=35, L_{G}=20$

\subsection{Information Topology with Partial-Intersect Type}

When information of the conspirators is partially intersected with that of the defender (i.e., $0<I_{G \cap P E}<\min$ $\left.\left(I_{G}, I_{P E}\right)\right)$, the sign symbol of $\operatorname{Det}(\lambda \omega, \rho)$ and $\operatorname{TrJ}(\lambda \omega, \rho)$ can be determined by Eq. (10). This condition can help obtain the ESS and replicated dynamic equation (Tab. 3).

Tab. 3 shows that when information of the conspirators is partially intersected with that of the defender, the following results can be concluded. (1) In case net earning of the government is positive, if the penalty factor $F_{P E}$ increased from less than the threshold to a high value, then 
the equilibrium strategy of the conspirators evolves from collusion $\left(\alpha_{1}\right)$ to non-collusion $\left(\alpha_{2}\right)$ while the equilibrium strategy of government regulation $\left(\beta_{1}\right)$. (2) In case net earning of the government is negative and the penalty factor $F_{P E}$ is less than the threshold, the equilibrium strategy of the conspirators is collusion $\left(\alpha_{1}\right)$ while that of the government evolves from non-regulation $\left(\beta_{2}\right)$ to regulation $\left(\beta_{1}\right)$ with the increasing shared information. (3) In case net earning of the government is negative and the penalty factor $F_{P E}$ is larger than the threshold, with the increase in shared information, the equilibrium strategies of the conspirators evolve from collusion $\left(\alpha_{1}\right)$ to non- equilibrium strategy while those of the government evolve from non-regulation $\left(\beta_{2}\right)$ to non-equilibrium strategy. Therefore, the collaborator and the defender partly possess shared information. In case net earning of the government from collusion-proof behavior is positive and the penalty factor is larger than the threshold, the ESS is $\left(\alpha_{2}, \beta_{1}\right)$. This condition means that the collusion will not occur (i.e., $\lambda=$ 0 or $\omega=0$ ).

Based on parameter assignment, sample phase portraits for $P E$ and $G$ under the replicator dynamics in Case 2(a) to Case 2(f) are given in Fig.4(1)-4(6).

Table 3 Equilibrium Point and Stability Analysis in Case $0<I_{G \cap P E}<\min \left(I_{G}, I_{P E}\right)$

\begin{tabular}{|c|c|c|c|c|}
\hline Variable Value & Equilibrium Point & $\operatorname{DetJ}(\lambda \omega, \rho)$ & $\operatorname{TrJ}(\lambda \omega, \rho)$ & Stability \\
\hline \multirow{4}{*}{ 2(a) $V_{G}>C_{G}$ and $F_{P E}<\frac{I_{P E}\left(V_{P E}-C_{P E}\right)-I_{G \cap P E} V_{P E}}{I_{G}-I_{G \cap P E}}$} & $\mathrm{E}(0,0)$ & + & + & instability \\
\hline & $\mathrm{E}(0,1)$ & - & uncertainty & saddle point \\
\hline & $\mathrm{E}(1,0)$ & - & uncertainty & saddle point \\
\hline & $\mathrm{E}(1,1)$ & + & - & ESS \\
\hline \multirow{4}{*}{ 2(b) $V_{G}>C_{G}$ and $F_{P E}>\frac{I_{P E}\left(V_{P E}-C_{P E}\right)-I_{G \cap P E} V_{P E}}{I_{G}-I_{G \cap P E}}$} & $\mathrm{E}(0,0)$ & + & + & instability \\
\hline & $\mathrm{E}(0,1)$ & + & - & ESS \\
\hline & $\mathrm{E}(1,0)$ & - & uncertainty & saddle point \\
\hline & $\mathrm{E}(1,1)$ & - & uncertainty & saddle point \\
\hline \multirow{4}{*}{$\begin{array}{l}\text { 2(c) } V_{G}<C_{G} \text { and } F_{P E}<\frac{I_{P E}\left(V_{P E}-C_{P E}\right)-I_{G \cap P E} V_{P E}}{I_{G}-I_{G \cap P E}} \\
\text { and } 0<I_{G \cap P E}<\min \left[\frac{I_{G}\left(C_{G}-V_{G}\right)}{L_{G}}, I_{G}, I_{P E}\right]\end{array}$} & $\mathrm{E}(0,0)$ & - & uncertainty & saddle point \\
\hline & $\mathrm{E}(0,1)$ & + & + & instability \\
\hline & $\mathrm{E}(1,0)$ & + & - & ESS \\
\hline & $\mathrm{E}(1,1)$ & - & uncertainty & saddle point \\
\hline \multirow{4}{*}{ 2(d) $V_{G}<C_{G}$ and $F_{P E}<\frac{I_{P E}\left(V_{P E}-C_{P E}\right)-I_{G \cap P E} V_{P E}}{I_{G}-I_{G \cap P E}}$} & $\mathrm{E}(0,0)$ & - & uncertainty & saddle point \\
\hline & $\mathrm{E}(0,1)$ & - & uncertainty & saddle point \\
\hline & $\mathrm{E}(1,0)$ & + & - & ESS \\
\hline & $\mathrm{E}(1,1)$ & + & + & instability \\
\hline \multirow{4}{*}{$\begin{array}{c}\text { 2(e) } V_{G}<C_{G} \text { and } F_{P E}>\frac{I_{P E}\left(V_{P E}-C_{P E}\right)-I_{G \cap P E} V_{P E}}{I_{G}-I_{G \cap P E}} \\
\text { and } 0<I_{G \cap P E}<\min \left[\frac{I_{G}\left(C_{G}-V_{G}\right)}{L_{G}}, I_{G}, I_{P E}\right]\end{array}$} & $\mathrm{E}(0,0)$ & - & uncertainty & saddle point \\
\hline & $\mathrm{E}(0,1)$ & - & uncertainty & saddle point \\
\hline & $\mathrm{E}(1,0)$ & + & - & ESS \\
\hline & $\mathrm{E}(1,1)$ & + & + & instability \\
\hline \multirow{5}{*}{ 2(f) $V_{G}<C_{G}$ and $F_{P E}>\frac{I_{P E}\left(V_{P E}-C_{P E}\right)-I_{G \cap P E} V_{P E}}{I_{G}-I_{G \cap P E}}$} & $\mathrm{E}(0,0)$ & - & uncertainty & saddle point \\
\hline & $\mathrm{E}(0,1)$ & - & uncertainty & saddle point \\
\hline & $\mathrm{E}(1,0)$ & - & uncertainty & saddle point \\
\hline & $\mathrm{E}(1,1)$ & - & uncertainty & saddle point \\
\hline & $\mathrm{E}\left(\lambda \omega^{*}, \rho^{*}\right)$ & + & 0 & center \\
\hline
\end{tabular}
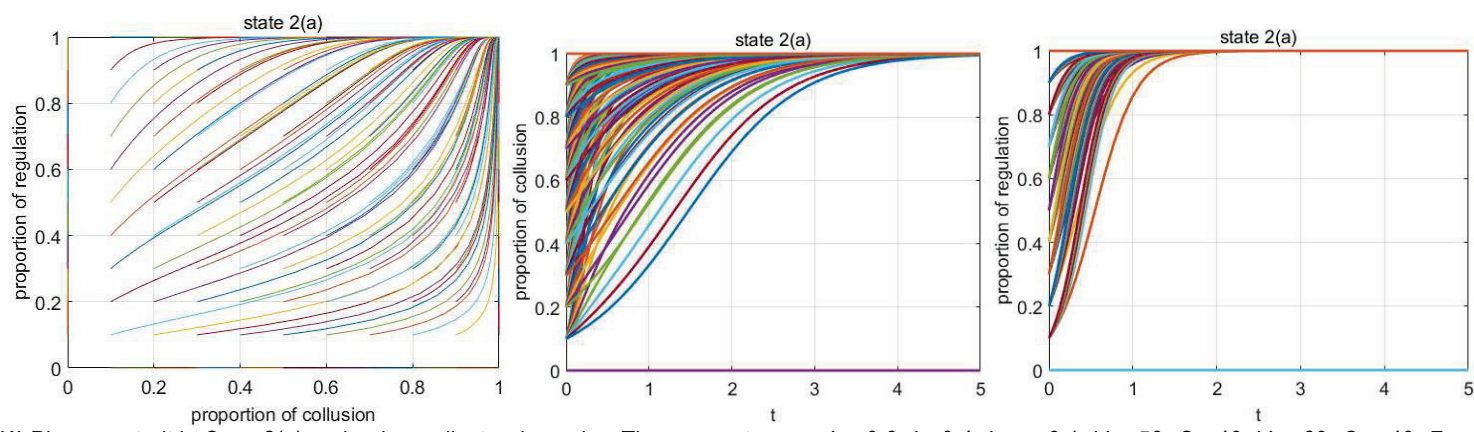

Figure 4(1) Phase portrait in Case 2(a) under the replicator dynamics. The parameters are $I_{P E}=0.6, I_{G}=0.4, I_{G \cap P E}=0.1, V_{G}=50, C_{G}=40, V_{P E}=60, C_{P E}=40, F_{P E}=15, L_{G}=20$
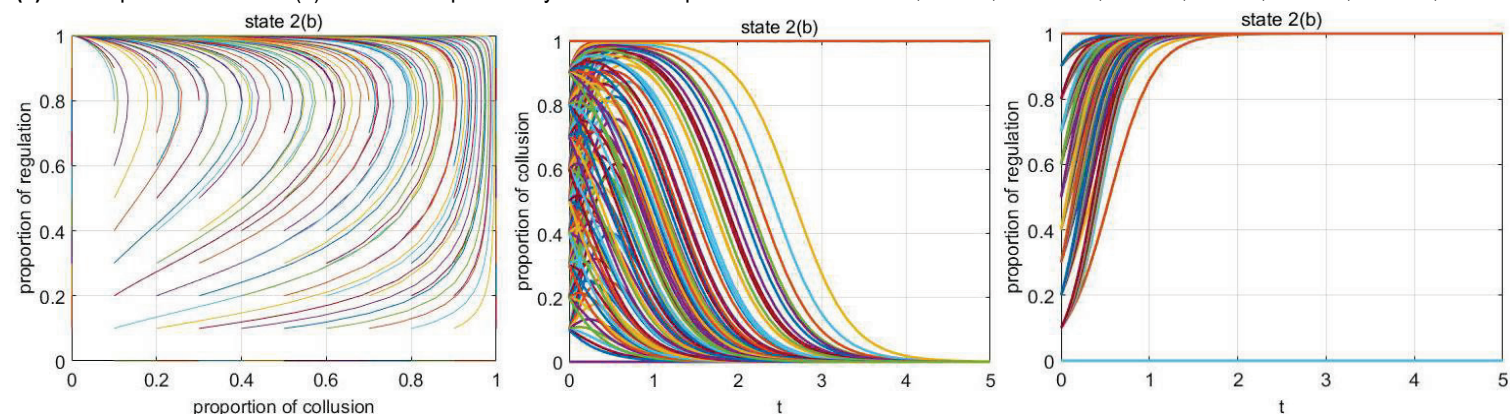

Figure 4(2) Phase portrait in Case 2(b) under the replicator dynamics. The parameters are $I_{P E}=0.6, I_{G}=0.4, I_{G \cap P E}=0.1, V_{G}=50, C_{G}=40, V_{E 1 E 2}=60, C_{E 1 E 2}=40, F_{E 1 E 2}=30, L_{G}=20$ 

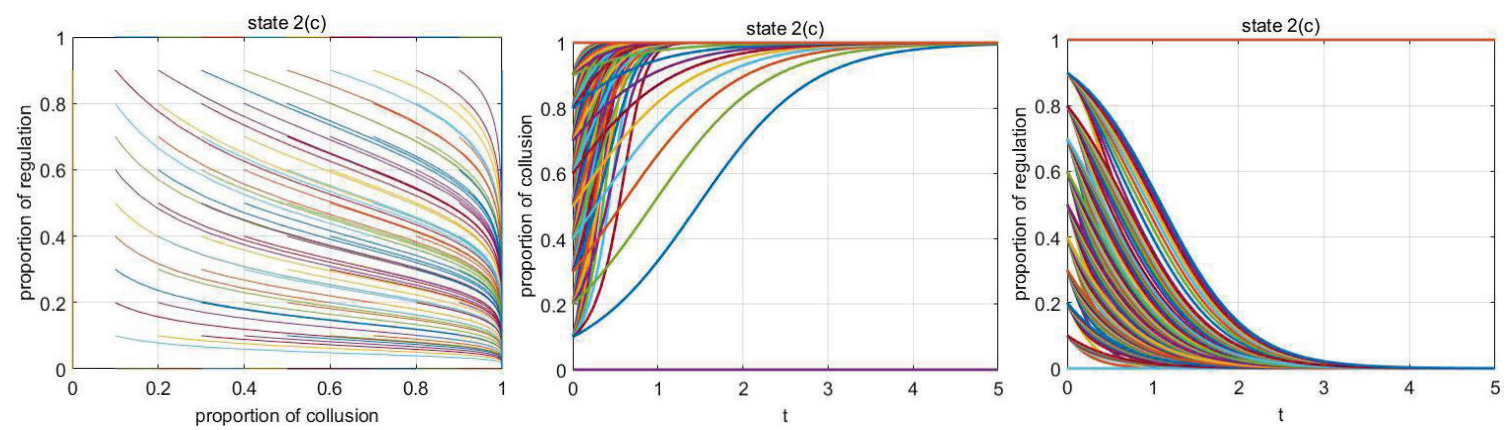

Figure 4(3) Phase portrait in Case 2(c) under the replicator dynamics. The parameters are $I_{P E}=0.6, I_{G}=0.4, I_{G \cap P E}=0.1, V_{G}=20, C_{G}=30, V_{P E}=60, C_{P E}=40, F_{P E}=15, L_{G}=20$
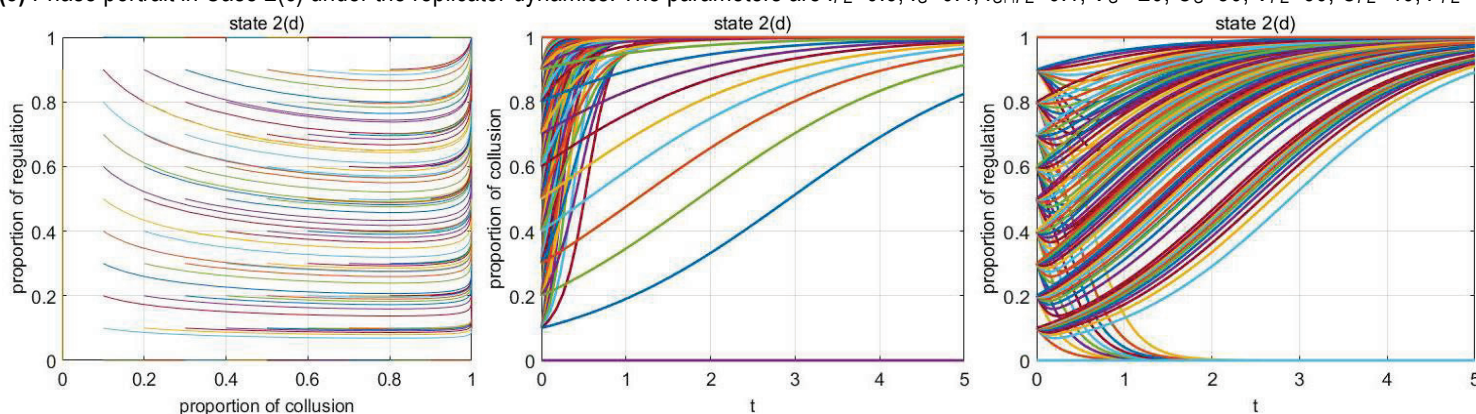

Figure 4(4) Phase portrait in Case 2(d) under the replicator dynamics. The parameters are $I_{P E}=0.6, I_{G}=0.4, I_{G \cap P E}=0.25, V_{G}=20, C_{G}=30, V_{P E}=60, C_{P E}=30, F_{P E}=15, L_{G}=20$
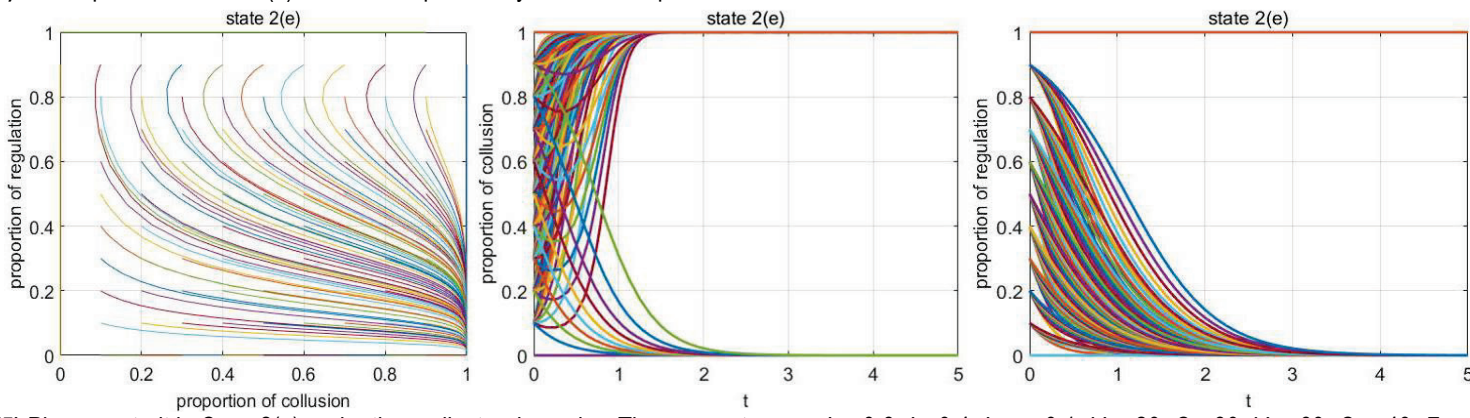

Figure 4(5) Phase portrait in Case 2(e) under the replicator dynamics. The parameters are $I_{P E}=0.6, I_{G}=0.4, I_{G \cap P E}=0.1, V_{G}=20, C_{G}=30, V_{P E}=60, C_{P E}=40, F_{P E}=30, L_{G}=20$
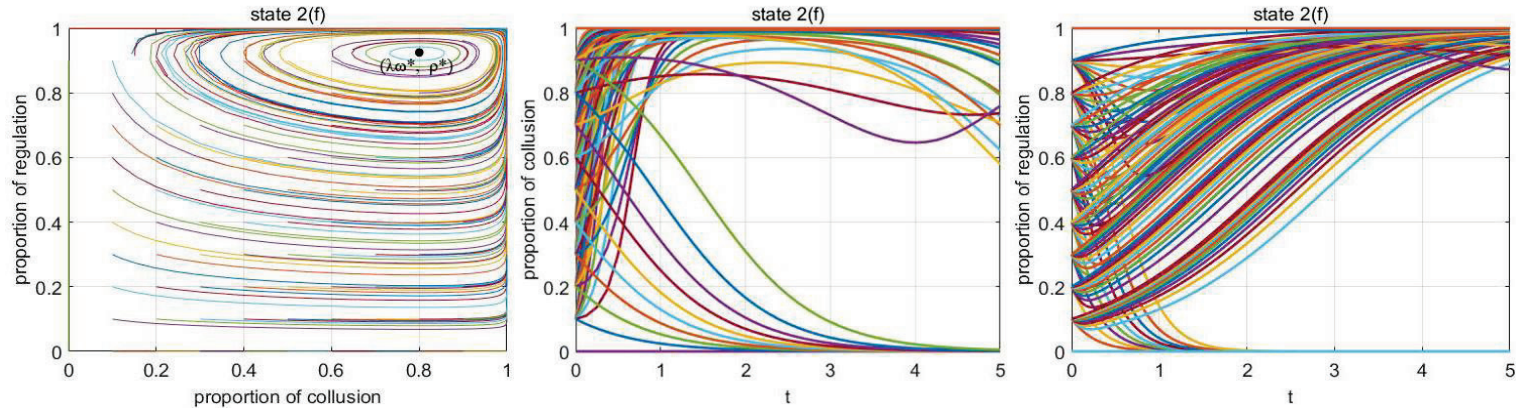

Figure 4(6) Phase portrait in Case 2(f) under the replicator dynamics. The parameters are $I_{P E}=0.6, I_{G}=0.4, I_{G \cap P E}=0.25, V_{G}=20, C_{G}=30, V_{P E}=60, C_{P E}=30, F_{P E}=30, L_{G}=20$

\subsection{Information Topology with Inclusive Type I $\left(I_{G} \subset I_{P E}\right)$}

When information of the conspirators contains that of the defender (i.e., $\left.I_{G} \subset I_{P E}\right)$, the sign symbol of $\operatorname{Det}(\lambda \omega, \rho)$ and $\operatorname{Tr} \mathrm{J}(\lambda \omega, \rho)$ can be determined by Eq. (10), which will help obtain the ESS and replicated dynamic equation (Tab. 4).

Tab. 4 shows that in case $I_{G} \subset I_{P E}$ (i.e., $I_{G \cap P E}=I_{G}$ ), the following results can be concluded:(1) If net earnings of the government from collusion-proof behavior are larger than those from non-regulation earnings, then the equilibrium strategy of the conspirators evolves from collusion $\left(\alpha_{1}\right)$ to non-collusion $\left(\alpha_{2}\right)$ then to non-equilibrium strategy while that of the government evolves from regulation $\left(\beta_{1}\right)$ to non-equilibrium strategy. (2) If net earnings of the government from collusion-proof behavior are less than those from non-regulation earnings, then the equilibrium strategy of the conspirators is collusion $\left(\alpha_{1}\right)$ while that of the government is non-regulation $\left(\beta_{2}\right)$. Therefore, in case $I_{G \cap P E}=I_{G}$, the penalty factor $F_{P E}$ will lose its regulatory role. For anti-collusion, net earnings of the government from collusion-proof behavior must be larger than those from non-regulation earnings, and the amount of information obtained by the government increases. Particularly, when net earnings of the government from collusion-proof behavior are positive and information obtained by the government is larger than the threshold, the ESS is $\left(\alpha_{2}, \beta_{1}\right)$. This finding means that the failed projects and the third party do not demonstrate a collusion tendency (i.e., $\lambda=0$ or $\omega=0$ ) while the government tends to keep collusion under strict supervision.

Based on parameter assignment, sample phase portraits for $P E$ and $G$ under the replicator dynamics in Case 3(a) to Case 3(f) are given in Figs. 5(1)-5(6). 
Table 4 Equilibrium Point and Stability Analysis in Case $I_{G} \subset I_{P E}$

\begin{tabular}{|c|c|c|c|c|}
\hline Variable Value & Equilibrium Point & $\operatorname{Det}(\lambda \omega, \rho)$ & $\operatorname{TrJ}(\lambda \omega, \rho)$ & Stability \\
\hline \multirow{4}{*}{ 3(a) $V_{G}>C_{G}$ and $0<I_{G \cap P E}<\frac{I_{P E}\left(V_{P E}-C_{P E}\right)}{V_{P E}}$} & $\mathrm{E}(0,0)$ & + & + & instability \\
\hline & $\mathrm{E}(0,1)$ & - & uncertainty & saddle point \\
\hline & $\mathrm{E}(1,0)$ & - & uncertainty & saddle point \\
\hline & $\mathrm{E}(1,1)$ & + & - & ESS \\
\hline \multirow{4}{*}{ 3(b) $-L_{G}<V_{G}-C_{G}<0$ and $0<I_{G \cap P E}<\frac{I_{P E}\left(V_{P E}-C_{P E}\right)}{V_{P E}}$} & $\mathrm{E}(0,0)$ & - & uncertainty & saddle point \\
\hline & $\mathrm{E}(0,1)$ & + & + & instability \\
\hline & $\mathrm{E}(1,0)$ & - & uncertainty & saddle point \\
\hline & $\mathrm{E}(1,1)$ & + & - & ESS \\
\hline \multirow{4}{*}{ 3(c) $V_{G}>C_{G}$ and $\frac{I_{P E}\left(V_{P E}-C_{P E}\right)}{V_{P E}}<I_{G \cap P E}<I_{P E}$} & $\mathrm{E}(0,0)$ & + & + & instability \\
\hline & $\mathrm{E}(0,1)$ & + & - & ESS \\
\hline & $\mathrm{E}(1,0)$ & - & uncertainty & saddle point \\
\hline & $\mathrm{E}(1,1)$ & - & uncertainty & saddle point \\
\hline \multirow{5}{*}{$3(\mathrm{~d})-L_{G}<V_{G}-C_{G}<0$ and $\frac{I_{P E}\left(V_{P E}-C_{P E}\right)}{V_{P E}}<I_{G \cap P E}<I_{P E}$} & $\mathrm{E}(0,0)$ & - & uncertainty & saddle point \\
\hline & $\mathrm{E}(0,1)$ & - & uncertainty & saddle point \\
\hline & $\mathrm{E}(1,0)$ & - & uncertainty & saddle point \\
\hline & $\mathrm{E}(1,1)$ & - & uncertainty & saddle point \\
\hline & $\mathrm{E}\left(\lambda \omega^{*}, \rho^{*}\right)$ & + & 0 & center \\
\hline \multirow{4}{*}{ 3(e) $V_{G}-C_{G}<-L_{G}$ and $0<I_{G \cap P E}<\frac{I_{P E}\left(V_{P E}-C_{P E}\right)}{V_{P E}}$} & $\mathrm{E}(0,0)$ & - & uncertainty & saddle point \\
\hline & $\mathrm{E}(0,1)$ & + & + & instability \\
\hline & $\mathrm{E}(1,0)$ & + & - & ESS \\
\hline & $\mathrm{E}(1,1)$ & - & uncertainty & saddle point \\
\hline \multirow{4}{*}{ 3(f) $V_{G}-C_{G}<-L_{G}$ and $\frac{I_{P E}\left(V_{P E}-C_{P E}\right)}{V_{P E}}<I_{G \cap P E}<I_{P E}$} & $\mathrm{E}(0,0)$ & - & uncertainty & saddle point \\
\hline & $\mathrm{E}(0,1)$ & - & uncertainty & saddle point \\
\hline & $\mathrm{E}(1,0)$ & + & - & ESS \\
\hline & $\mathrm{E}(1,1)$ & + & + & instability \\
\hline
\end{tabular}
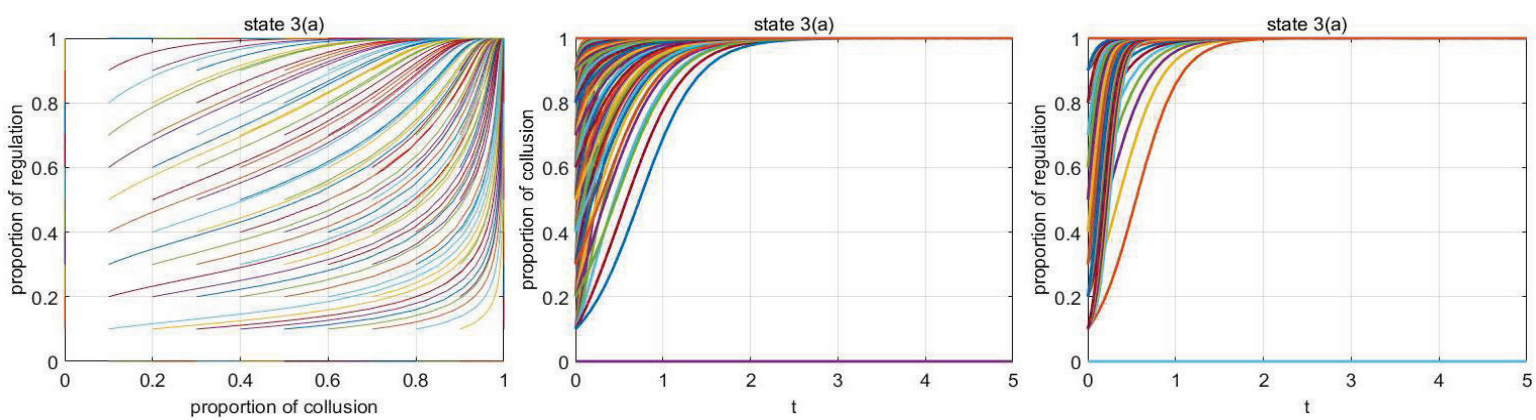

Figure 5(1)Phase portrait in Case $3(\mathrm{a})$ under the replicator dynamics. The parameters are $I_{P E}=0.6, I_{G}=0.4, I_{G \cap P E}=0.4, V_{G}=50, C_{G}=40, V_{P E}=60, C_{P E}=15, F_{P E}=15, L_{G}=20$
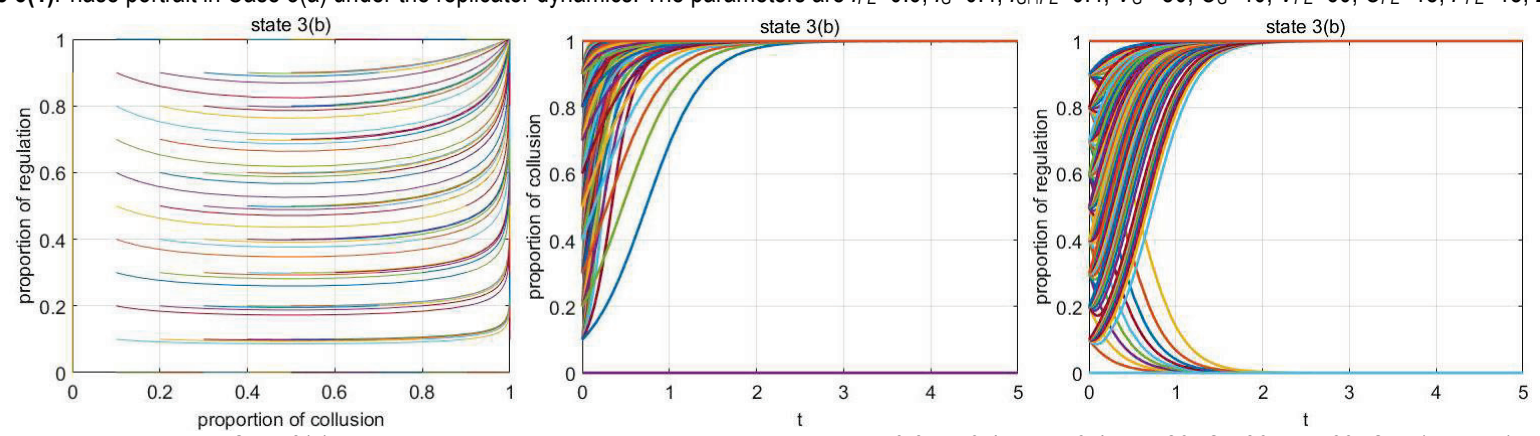

Figure 5(2) Phase portrait in Case 3(b) under the replicator dynamics. The parameters are $I_{P E}=0.6, I_{G}=0.4, I_{G \cap P E}=0.4, V_{G}=20, C_{G}=30, V_{P E}=60, C_{P E}=15, F_{P E}=15, L_{G}=20$
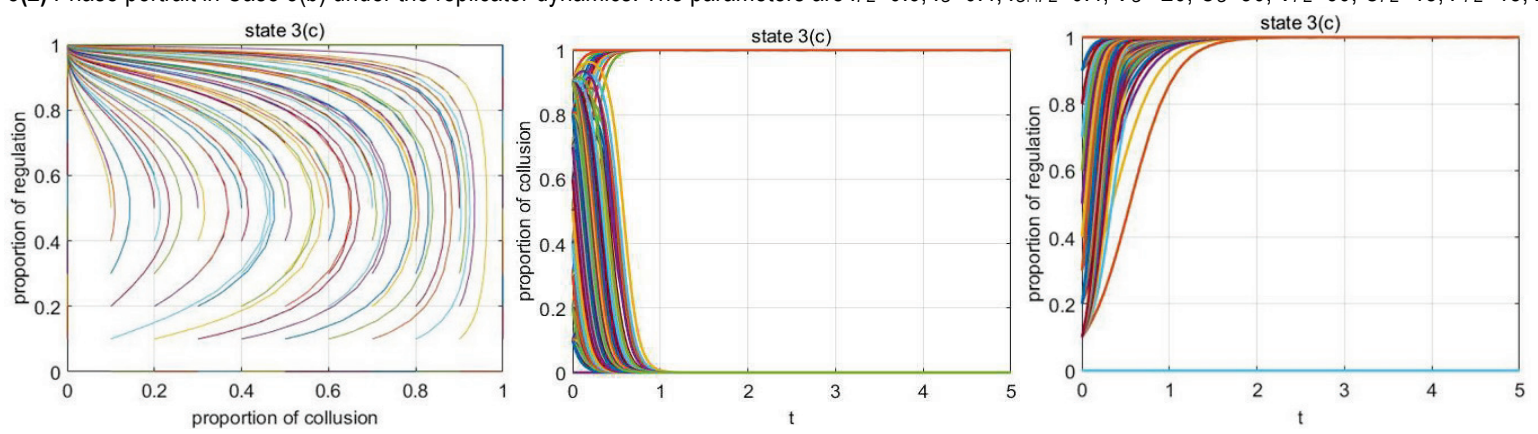

Figure 5(3) Phase portrait in Case $3(c)$ under the replicator dynamics. The parameters are $I_{P E}=0.6, I_{G}=0.4, I_{G \cap P E}=0.4, V_{G}=50, C_{G}=40, V_{P E}=60, C_{P E}=40, F_{P E}=15, L_{G}=20$ 

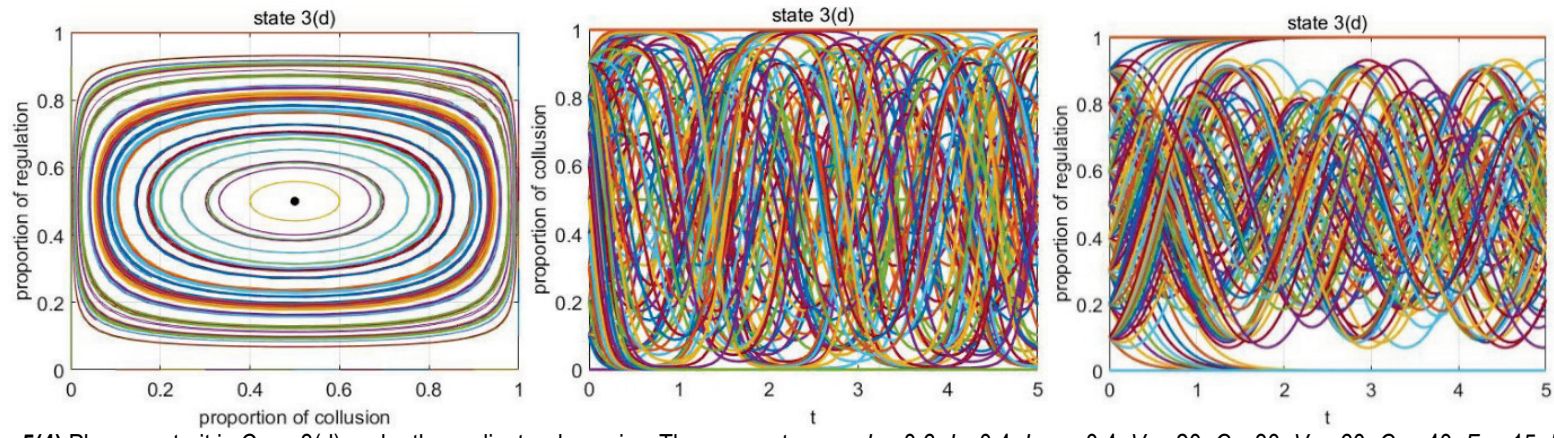

Figure 5(4) Phase portrait in Case $3(\mathrm{~d})$ under the replicator dynamics. The parameters are $I_{P E}=0.6, I_{G}=0.4, I_{G \cap P E}=0.4, V_{G}=20, C_{G}=30, V_{P E}=60, C_{P E}=40, F_{P E}=15, L_{G}=20$
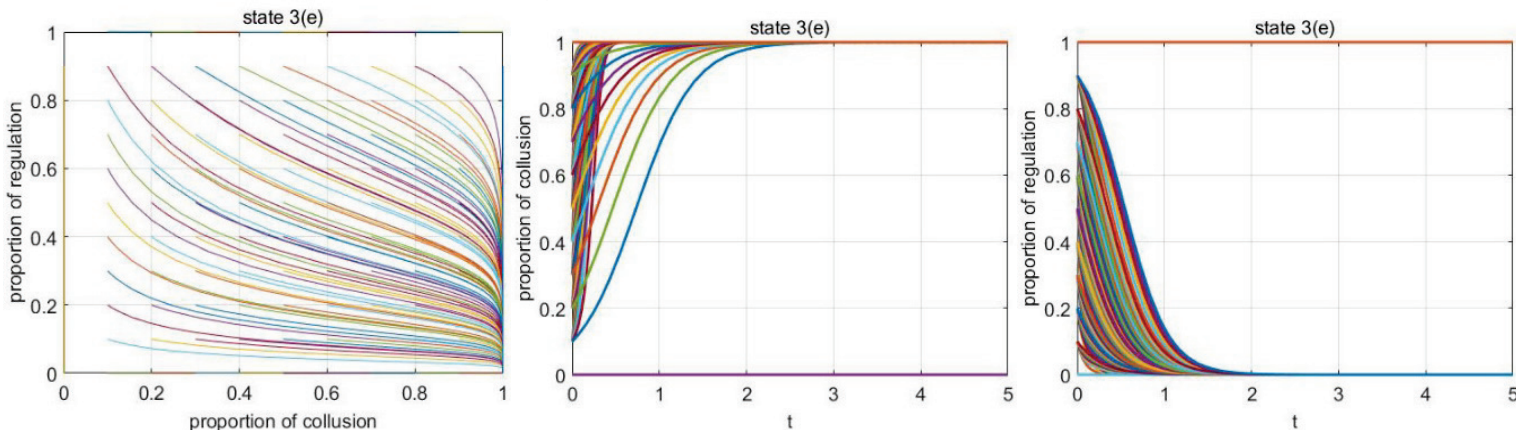

Figure 5(5) Phase portrait in Case 3(e) under the replicator dynamics. The parameters are $I_{P E}=0.6, I_{G}=0.4, I_{G \cap P E}=0.4, V_{G}=20, C_{G}=50, V_{P E}=60, C_{P E}=15, F_{P E}=15, L_{G}=20$
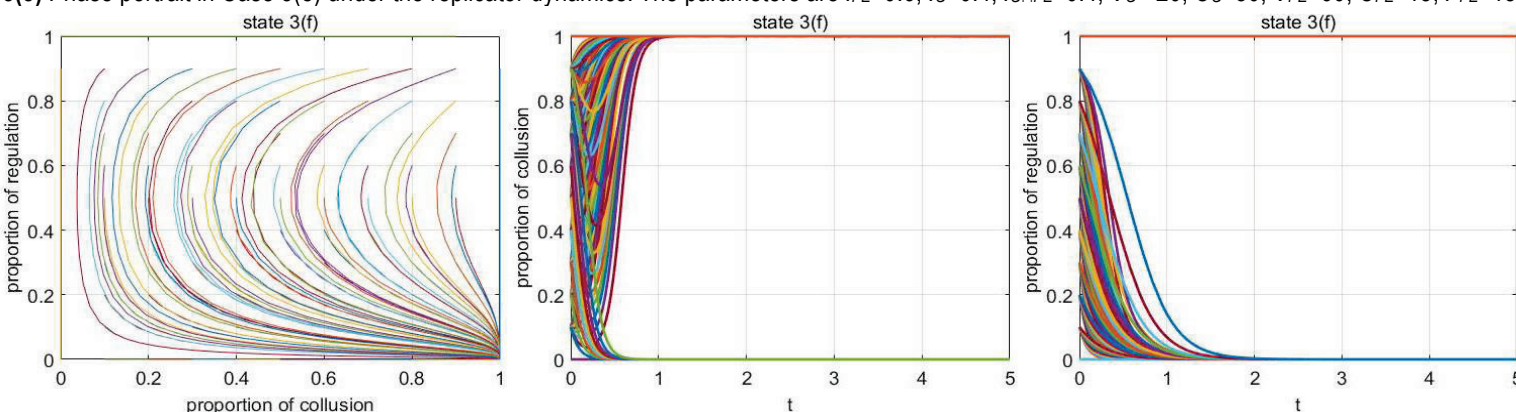

Figure 5(6) Phase portrait in Case 3(f) under the replicator dynamics. The parameters are $I_{P E}=0.6, I_{G}=0.4, I_{G \cap P E}=0.4, V_{G}=20, C_{G}=50, V_{P E}=60, C_{P E}=40, F_{P E}=15, L_{G}=20$

Table 5 Equilibrium Point and Stability Analysis in Case $I_{P E} \subset I_{G}$

\begin{tabular}{|c|c|c|c|c|}
\hline Variable Value & Equilibrium Point & $\operatorname{DetJ}(\lambda \omega, \rho)$ & $\operatorname{TrJ}(\lambda \omega, \rho)$ & Stability \\
\hline \multirow{4}{*}{ 4(a) $V_{G}>C_{G}$} & $\mathrm{E}(0,0)$ & + & + & instability \\
\hline & $\mathrm{E}(0,1)$ & + & - & ESS \\
\hline & $\mathrm{E}(1,0)$ & - & uncertainty & saddle point \\
\hline & $\mathrm{E}(1,1)$ & - & uncertainty & saddle point \\
\hline \multirow{4}{*}{ 4(b) $V_{G}>C_{G}$ and $0<I_{G \cap P E}<\min \left[\frac{I_{G}\left(C_{G}-V_{G}\right)}{L_{G}}, I_{G}\right]$} & $\mathrm{E}(0,0)$ & - & uncertainty & saddle point \\
\hline & $\mathrm{E}(0,1)$ & - & uncertainty & saddle point \\
\hline & $\mathrm{E}(1,0)$ & + & - & ESS \\
\hline & $\mathrm{E}(1,1)$ & + & + & instability \\
\hline \multirow{5}{*}{ 4(c) $V_{G}<C_{G}$ and $\frac{I_{G}\left(C_{G}-V_{G}\right)}{L_{G}}<I_{G \cap P E}<I_{G}$} & $\mathrm{E}(0,0)$ & - & uncertainty & saddle point \\
\hline & $\mathrm{E}(0,1)$ & - & uncertainty & saddle point \\
\hline & $\mathrm{E}(1,0)$ & - & uncertainty & saddle point \\
\hline & $\mathrm{E}(1,1)$ & - & uncertainty & saddle point \\
\hline & $\mathrm{E}\left(\lambda \omega^{*}, \rho^{*}\right)$ & + & 0 & center \\
\hline
\end{tabular}

\subsection{Information Topology with Inclusive Type II $\left(I_{P E} \subset I_{G}\right)$}

When information of the conspirators is more contained than that of the defender (i.e., $I_{P E} \subset I_{G}$ ), the sign symbol of $\operatorname{Det} \mathrm{J}(\lambda \omega, \rho)$ and $\operatorname{Tr} \mathrm{J}(\lambda \omega, \rho)$ can be determined by Eq. (10), which will help obtain the ESS and replicated dynamic equation (Tab. 5).

Tab. 5 shows that in case $I_{P E} \subset I_{G}$ (i.e., $I_{G \cap P E}=I_{P E}$ ), the following results can be concluded.(1) If net earnings of the government from collusion-proof behavior are positive, then the equilibrium strategy of the conspirators is noncollusion $\left(\alpha_{2}\right)$ while that of the government is regulation $\left(\beta_{1}\right)$. (2) If net earnings of the government from collusionproof behavior are negative, then the equilibrium strategy of the conspirators evolves from collusion $\left(\alpha_{1}\right)$ to nonequilibrium strategy while that of the government evolves from non-regulation $\left(\beta_{2}\right)$ to non-equilibrium strategy. Therefore, in case $I_{P E} \subset I_{G}$ (i.e., $I_{G \cap P E}=I_{P E}$ ), the penalty factor $F_{P E}$ will lose its regulatory role. For anti-collusion, the penalty factor can increase the amount of information grasped by the government. When the net earnings of the government from collusion-proof behavior are positive, the ESS is $\left(\alpha_{2}, \beta_{1}\right)$, which means that the enterprise and the third party do not demonstrate a collusion tendency (i.e., $\lambda$ $=0$ or $\omega=0$ ) while the government tends to keep them under strict supervision.

Based on parameter assignment, sample phase portraits for $P E$ and $G$ under the replicator dynamics in 
Case 4(a) to Case 4(c) are given in Fig. 6(1)-6(3).
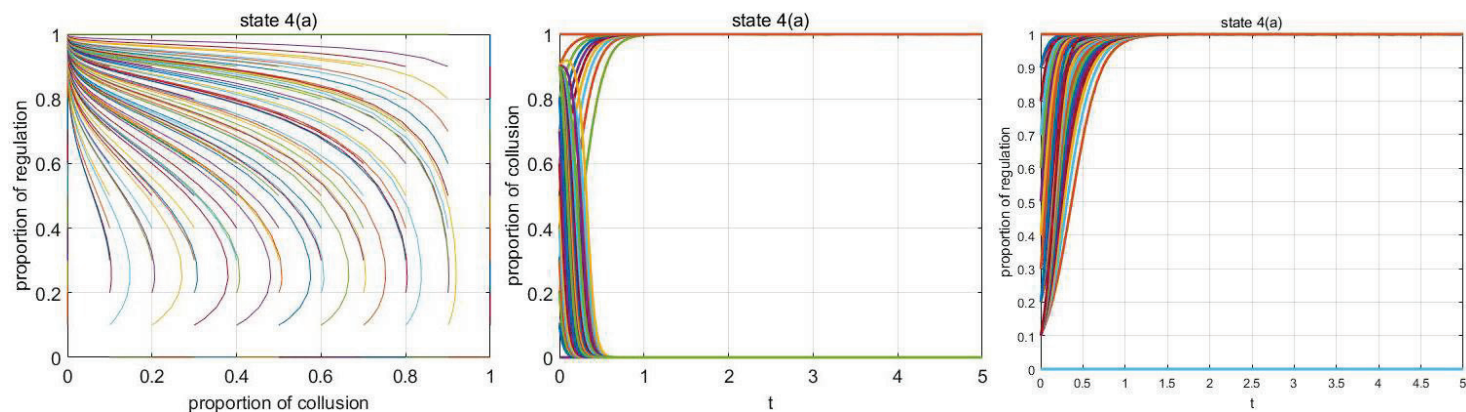

Figure 6(1) Phase portrait in Case $4(a)$ under the replicator dynamics. The parameters are $I_{P E}=0.4, I_{G}=0.6, I_{G \cap P E}=0.4, V_{G}=50, C_{G}=40, V_{P E}=60, C_{P E}=40, F_{P E}=35, L_{G}=20$
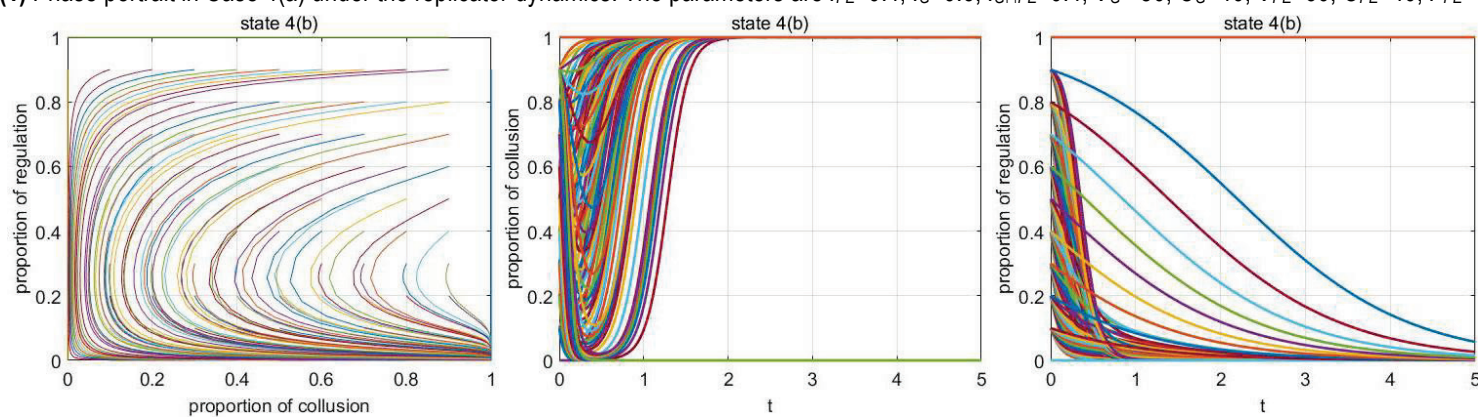

Figure 6(2) Phase portrait in Case 4 (b) under the replicator dynamics. The parameters are $I_{P E}=0.4, I_{G}=0.6, I_{G \cap P E}=0.4, V_{G}=15, C_{G}=30, V_{P E}=60, C_{P E}=40, F_{P E}=35, L_{G}=20$
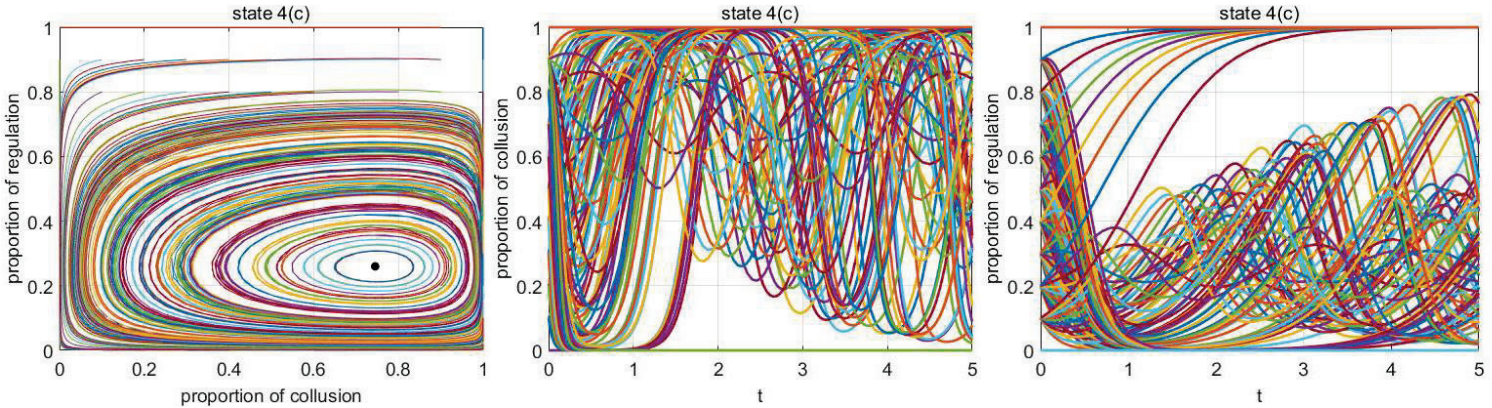

Figure 6(3) Phase portrait in Case 4 (c) under the replicator dynamics. The parameters are $I_{P E}=0.4, I_{G}=0.6, I_{G \cap P E}=0.4, V_{G}=20, C_{G}=30, V_{P E}=60, C_{P E}=40, F_{P E}=35, L_{G}=20$

\subsection{Further Discussion}

According to the evolutionary stability analysis under the four types of information topology, the evolutionary stability strategy of collusion-proof game is $\left(\alpha_{2}, \beta_{1}\right)$ when the following conditions are met: (1) $V_{G}>C_{G}$ and $F_{P E}>$ $\left[I_{P E}\left(V_{P E}-C_{P E}\right)\right] / I_{G}$ in Case $I_{G \cap P E}=0$; (2) $V_{G}>C_{G}$ and $F_{P E}$ $>\left[I_{P E}\left(V_{P E}-C_{P E}\right)-I_{G \cap P E} V_{P E}\right] /\left(I_{G}-I_{G \cap P E}\right)$ in Case $0<I_{G \cap P E}$ $<\min \left(I_{G}, I_{P E}\right)$; (3) $V_{G}>C_{G}$ and $\left[I_{P E}\left(V_{P E}-C_{P E}\right) / V_{P E}\right]<$ $I_{G \cap P E}<I_{P E}$ in Case $I_{G} \subset I_{P E}$; (4) $V_{G}>C_{G}$ in Case $I_{P E} \subset I_{G}$.

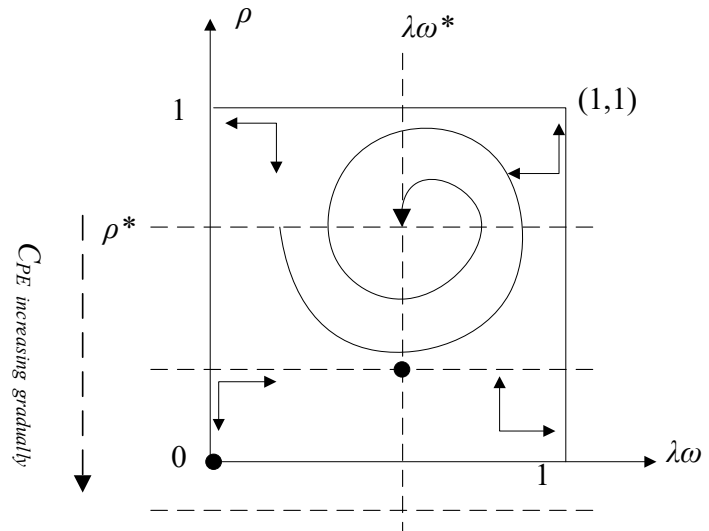

Figure 7 Phase Portraitin Case Increasing of $C_{P E}$
Furthermore, considering the non-equilibrium strategy $\mathrm{E}\left(\lambda \omega^{*}, \rho^{*}\right)$, the group proportion of the conspirators with collusion strategy is $\lambda \omega^{*}$ while that of the government with regulation strategy is $\rho^{*}$; this condition is close to the actual situation in the real world. In case the collusive cost $C_{E I E 2}$ increases to a certain degree, the collusive probability $\lambda \omega^{*}$ under bounded rationality will not change correspondingly while the regulatory probability of the government $\rho^{*}$ will decrease correspondingly. This phenomenon means that the center of the evolutionary game model will move down (Fig. 7). However, in case collusive cost $C_{P E}$ rises to the same level as collusive income $V_{P E}$, the collusive probability $\lambda \omega^{*}$ under bounded rationality will be equal to 0 . The government will take measures to increase the collusive cost to reduce the collusive probability. In case $C_{P E}<V_{P E}, \lambda \omega^{*}$ will not change while $\rho^{*}$ will decrease correspondingly. This condition indicates that the collusive probability will not decrease with increasing collusive cost promoted by the government. On the contrary, regulatory probabilities of the government will decrease. Meanwhile, the collusive probability will progressively increase when detected by the conspirators, prompting the government to provide additional social resources. Therefore, if the government tends to increase the difficulty of collusion for anti-collusion, then the collusive cost must be larger than the collusive income; otherwise, rushing into action is discouraged. 


\section{CONCLUSION}

The collusion-proof issue is an important part of institutional economics, and game theory is an important analytical tool for this field. Considering the potential collusive behavior between failed generic technological innovation projects and the third party, this study sets the government as the supervisor under the four types of information topology (non-intersect, partial-intersect, and inclusive type) to analyze the collusion-proof game for anti-collusion. Then, the evolutionary stability results can be concluded as follows:

(1) In non-intersecting type, the government fails to gain access to the collusive information. Collusion between the failed generic technological innovation projects and the third party could only be effectively avoided if the net defense income is increased and the punishment is strengthened. Otherwise, the collusion will be inevitable. (2) With the increasing amount of collusive information available to the government, the collusive behavior can be limited to a certain extent, and potential conspirators tend to adhere to the moral principles or be fearful of strict regulation. (3) The regulatory role of the penalty factor is positively correlated with the amount of private information for each party. If the conspirators and the defender both have private information, then the punishment effect on collusion is significant; otherwise, the effect is insignificant. (4) Partial-intersect type is a general defense situation. In this case, if the net collusive income is still positive, instead of anti-collusion by increasing the collusive cost, then the regulatory behavior of the government will be restrained.

Given the social network characteristics of compensation for failed generic technological innovation projects, considering multi-population structural factors in the social network will further explain the game model in accordance with the social reality. Simultaneously, bounded rationality of the conspirators can be further discussed through building moral choice models or deterrent perception functions based on the regulation efficiency of the government. This approach is conducted for further testing of the regulation efficiency of the government restrains the collusive tendency through influencing the perception of deterrence of conspirators. Meanwhile, different types of compensation mode (e.g., minimum guarantee for loss, compensation for loss, compensation for income, and exclusive of income or risk) and suitable game models can be designed with appropriate emulation technique to simulate and test the collusionproof mechanism despite the lack of practical compensation data for failed generic technological innovation projects. In addition, this study discusses the probability fluctuation of collusion and regulation, which provides another option in terms of solving the collusive problem of compensation and introduces corresponding risks. However, for this situation, reducing the probability of collusion and avoiding corresponding risks must be explored in the future.

Finally, compared with the general 22 static games, the evolutionary game model established in this paper analyzes the game behaviours of the players in the process of compensation for generic technological innovation failures, which conforms to the reality. However, in the long run, it is far from enough to rely solely on government efforts as the government should not only implement compensations but also maintain a regulatory mechanism, whose effectiveness and efficiency will both be affected by its limited and insufficient resources. Therefore, in this regard, joint efforts are required from all walks of life. On the other hand, in the evolutionary game model, the factors that affect the subject behaviours in the compensation process are not fully considered, so the target selection and collusion-proof mechanism cannot be fully revealed and restored. This indicates that more factors should be incorporated to be more consistent with the actual situation, so that more practical countermeasures and suggestions will be put forward in future studies.

\section{Acknowledgements}

This study was supported by "the Fundamental Research Funds for the Central Universities" (Grant no. 2017-YB-016).

\section{REFERENCES}

[1] Choi, J. \& Lee, J. (2017). Repairing the R\&D market failure: public R\&D subsidy and the composition of private R\&D, Research Policy, 46(8), 1465-1478. https://doi.org/10.1016/j.respol.2017.06.009

[2] Roschk, H. \& Gelbrich, K. (2014). Identifying appropriate compensation types for service failures: a meta-analytic and experimental analysis. Journal of Service Research, 17(2), 195-211. https://doi.org/10.1177/1094670513507486

[3] Simona, M. (2018). Subsidies, financial constraints and firm innovative activities in emerging economies. Small Business Economics, 50(1), 131-162. https://doi.org/10.1007/s11187-017-9877-3

[4] Guzzini, E. \& Iacobucci, D. (2017). Project failures and innovation performance in university-firm collaborations. Journal of Technology Transfer, 42(4), 865-883. https://doi.org/10.1007/s10961-016-9554-8

[5] Andersen, M. S., Bray, J. W. \& Link, A. N. (2017). On the failure of scientific research: An analysis of SBIR projects funded by the US National Institutes of Health. Scientometrics, 112(1), 431-442. https://doi.org/10.1007/s11192-017-2353-7

[6] Savolainen, P., Ahonen J. J. \& Richardson, I. (2012). Software development project success and failure from the supplier's perspective: a systematic literature review. International Journal of Project Management, 30(4), 458469. https://doi.org/10.1016/j.jproman.2011.07.002

[7] Madsen, P. M. \& Desai, V. (2010). Failing to learn? The effects of failure and success on organizational learning in the global orbital launch vehicle industry. Academy of Management Journal, 53(3), 451-476. https://doi.org/10.5465/amj.2010.51467631

[8] Quevedob, J. G., Blascoa A. S. \& Teruel, M. (2018). Financial constraints and the failure of innovation projects. Technological Forecasting and Social Change, 127, 127140. https://doi.org/10.1016/j.techfore.2017.05.029

[9] Carmeli A. \& Dothan, A. (2017). Generative work relationships as a source of direct and indirect learning from experiences of failure: implications for innovation agility and product innovation. Technological Forecasting and Social Change, 119, 27-38. https://doi.org/10.1016/j.techfore.2017.03.007

[10] Athaide, G. A. \& Klink, R. R. (2009). Managing seller-buyer relationships during new product development. Journal of Product Innovation Management, 26(5), 566-577. 
https://doi.org/10.1111/j.1540-5885.2009.00681.x

[11] Arrow, K. J. (1962). The economic implications of learning by doing. Reviews of Economic Studies, 29, 155-173. https://doi.org/10.2307/2295952

[12] Artmann, S. (2012). Advising government how to address market failure in innovation and what about government failure? Science and Innovation Policy for the New Knowledge Economy. Science and Public Policy, 39(5), 690-691. https://doi.org/10.1093/scipol/scs035

[13] Cano-Kollmann, M., Hamilton III, R. D., \& Mudambi, R. (2017). Public support for innovation and the openness of firms' innovation activities. Industrial and Corporate Change, 26(3), 421-442.

[14] Czarnitzki, D., Hanel, P., \& Rosa, J. M. (2011). Evaluating the impact of R\&D tax credits on innovation: A microeconometric study on Canadian firms. Research Policy, 40(2), 217-229. https://doi.org/10.1016/j.respol.2010.09.017

[15] Bérubé, C. \& Mohnen, P. (2009). Are firms that receive R\&D subsidies more innovative? Canadian Journal of Economics, 42(1), 206-225. https://doi.org/10.1111/j.1540-5982.2008.01505.x

[16] Wolff, G. B. \& Reinthaler, V. (2008). The effectiveness of subsidies revisited: Accounting for wage and employment effects in business R\&D. Research Policy, 37(8), 1403-1412. https://doi.org/10.1016/j.respol.2008.04.023

[17] González, X. \& Pazó, C. (2008). Do Public Subsidies Stimulate Private R\&D Spending? Research Policy, 37(3), 371-389. https://doi.org/10.1016/j.respol.2007.10.009

[18] Xiong, Z., Ye, J. M., \& Wang, P. J. (2019). Does the institutional environment affect the failed technological innovation in firms? Evidence from listed companies in China's pharmaceutical manufacturing industry. Transformations in Business \& Economics, 18(1), 60-80.

[19] Gorg, H. \& Strobl, E. (2007). The effect of R\&D subsidies on private R\&D. Economica, 74(294), 215-234. https://doi.org/10.1111/j.1468-0335.2006.00547.x

[20] Guzzini, E. \& Iacobucci, D. (2017). Project failures and innovation performance in university-firm collaborations. Journal of Technology Transfer, 42(4), 865-883. https://doi.org/10.1007/s10961-016-9554-8

[21] Savolainen, P., Ahonen, J. J., \& Richardson, I. (2012). Software development project success and failure from the supplier's perspective: A systematic literature review. International Journal of Project Management, 30(4), 458469. https://doi.org/10.1016/j.jproman.2011.07.002

[22] David, M. (2016). Change and persistence with failed technological innovation. Strategic Management Journal, 37(4), 714-723. https://doi.org/10.1002/smj.2358

[23] Wadho, W. \& Ayaz, U. (2018). Government size and economic growth in an endogenous growth model with rentseeking. Economics \& Politics, 30(1), 151-179. https://doi.org/10.1111/ecpo.12105

[24] Miyazaki, Y. \& Azuma, H. (2013). ( $\lambda, \epsilon)$-stable model and essential equilibria. Mathematical Social Sciences, 65(2), 85-91. https://doi.org/10.1016/j.mathsocsci.2012.08.002

[25] Xue, L. (2013). Evolution of spatial structure of commerce center in global city-region: a dynamic agent-based simulation. Procedia-Social and Behavioral Sciences, 77, 308-321. https://doi.org/10.1016/j.sbspro.2013.03.089

[26] Erlei, M. \& Schenk-Mathes, H. (2017). Bounded rationality in principal-agent relationships. German Economic Review, 18(4), 411-443. https://doi.org/10.1111/geer.12111

[27] Haphuriwat, N. \& Bier, V. M. (2011). Trade-offs between target hardening and overarching protection. European Journal of Operational Research, 213(1), 320-328. https://doi.org/10.1016/j.ejor.2011.03.035

\section{Contact information:}

Fan ZHANG, PhD Candidate

(Corresponding author)

School of Management, Wuhan University of Technology

No. 122, Luoshi St. Wuhan, 430070, P. R. China

E-mail: zf050507239@163.com

Jianmu YE, Prof., PhD

School of Management, Wuhan University of Technology

No. 122, Luoshi St. Wuhan, 430070, P. R. China

E-mail: jianmuye@126.com

Congzhen XIE, PhD Candidate

School of Management, Wuhan University of Technology

No. 122, Luoshi St. Wuhan, 430070, P. R. China

E-mail:1309612065@qq.com 